\title{
Traffic lights for retinoids in oncology: molecular markers of retinoid resistance and sensitivity and their use in the management of cancer differentiation therapy
}

Viera Dobrotkova ${ }^{1,2}$, Petr Chlapek ${ }^{1,2}$, Pavel Mazanek ${ }^{3}$, Jaroslav Sterba ${ }^{2,3}$ and Renata Veselska ${ }^{1,2,3^{*}}$

\begin{abstract}
For decades, retinoids and their synthetic derivatives have been well established anticancer treatments due to their ability to regulate cell growth and induce cell differentiation and apoptosis. Many studies have reported the promising role of retinoids in attaining better outcomes for adult or pediatric patients suffering from several types of cancer, especially acute myeloid leukemia and neuroblastoma. However, even this promising differentiation therapy has some limitations: retinoid toxicity and intrinsic or acquired resistance have been observed in many patients. Therefore, the identification of molecular markers that predict the therapeutic response to retinoid treatment is undoubtedly important for retinoid use in clinical practice. The purpose of this review is to summarize the current knowledge on candidate markers, including both genetic alterations and protein markers, for retinoid resistance and sensitivity in human malignancies.
\end{abstract}

Keywords: Retinoids, Cell differentiation, Retinoid resistance, Retinoid sensitivity, Predictive biomarkers, Acute myeloid leukemia, Pancreatic ductal adenocarcinoma, Breast carcinoma, Neuroblastoma

\section{Introduction}

Defective or aberrant cell differentiation is a hallmark of many human malignancies. The initial step in an aberrant tumor cell phenotype involves various mutations that alter signaling pathways, epigenetic modifiers, and transcription factors, leading to the deregulated expression of proteins required for cell differentiation.

During the 1970s and 1980s, as an elegant alternative to killing cancer cells by cytotoxic therapies, several scientific achievements popularized the strategy of inducing malignant cells to overcome differentiation inhibition and to enter apoptotic pathways [1]. The initial preclinical results

\footnotetext{
* Correspondence: veselska@sci.muni.cz

${ }^{1}$ Laboratory of Tumor Biology, Department of Experimental Biology, Faculty

of Science, Masaryk University, Kotlarska 2, 61137 Brno, Czech Republic

${ }^{2}$ International Clinical Research Center, St. Anne's University Hospital,

Pekarska 53, 65691 Brno, Czech Republic

Full list of author information is available at the end of the article
}

proved to be very promising and fueled hope for the development of a new approach in cancer treatment called "differentiation therapy" [2].

In general, differentiation therapy aims to reactivate the endogenous differentiation program in transformed cells to resume the mutation process and eliminate the tumor phenotype. Thus, this strategy offers the prospect of a less aggressive treatment that limits damage to the normal cells in the organism.

\section{Natural and synthetic retinoids in anticancer treatment}

Retinoids, i.e., natural and synthetic vitamin A derivatives, have been studied for decades in clinical trials due to their established role in regulating cell growth, differentiation and apoptosis. Retinoids are key compounds in biological differentiation therapy. Retinoids have critical functions in many aspects of human biology: at the cellular level, they

(c) The Author(s). 2018 Open Access This article is distributed under the terms of the Creative Commons Attribution 4.0 International License (http://creativecommons.org/licenses/by/4.0/), which permits unrestricted use, distribution, and reproduction in any medium, provided you give appropriate credit to the original author(s) and the source, provide a link to the Creative Commons license, and indicate if changes were made. The Creative Commons Public Domain Dedication waiver (http://creativecommons.org/publicdomain/zero/1.0/) applies to the data made available in this article, unless otherwise stated. 
control cell differentiation, growth, and apoptosis [3]. Several biologically active vitamin A derivatives, namely, all-trans retinoic acid (ATRA), 9-cis retinoic acid (9-cis-RA), and 13-cis retinoic acid (13-cis-RA), have been tested for potential use in cancer therapy and chemoprevention [4-7]. The most effective clinical use of ATRA was demonstrated in acute promyelocytic leukemia (APL) treatment [8]. Additional studies have indicated that 13-cis-RA is beneficial in high-risk neuroblastoma (NBL) treatment after bone marrow transplantation, suggesting that retinoids may play an adjuvant therapeutic role in the management of minimal residual disease [9]. List of all human malignancies, for which the clinical treatment with retinoids was already tested, is given in the Table 1 .
Nevertheless, vitamin A-associated toxicity involving liver and lipid alterations, dry skin, teratogenicity, bone and connective tissue damage substantially limits the long-term administration of natural retinoids. Both ATRA and 13-cis RA are pan-RAR activators, which can explain their large negative side effects. For these reasons, the modification of several functional groups has produced new, synthetic retinoids that have increased chemoprevention efficacy and reduced toxicity compared with these parameters in other natural retinoids. These modifications include the substitution of benzoic acid with aromatic rings or can change their solubility in water, for example. Fenretinide (N-(4-hydroxyphenyl) retinamide, 4-HPR) has been discussed as an effective

Table 1 Overview of the human cancer types treated with retinoids in clinical studies

\begin{tabular}{|c|c|c|c|}
\hline Type of cancer & Retinoid & Type of treatment & Reference \\
\hline Acute myeloid leukemia & ATRA & Trial Phase III & {$[101]$} \\
\hline Acute promyelocytic leukemia & ATRA & Trial Phase IV & {$[8]$} \\
\hline B-cell lymphoma & Fenretinide & Trial Phase II & {$[102]$} \\
\hline Breast carcinoma & ATRA & Observational study & [103] \\
\hline Cervical carcinoma & 13-cis-RA & Trial Phase II & {$[104]$} \\
\hline Cutaneous T-cell lymphoma & Bexarotene & Trial Phase II-III & {$[105]$} \\
\hline \multirow[t]{2}{*}{ Ewing's sarcoma } & Fenretinide & Trial Phase I & {$[106]$} \\
\hline & 13-cis-RA & Observational study & {$[107]$} \\
\hline Glioblastoma multiforme & 13-cis-RA & Trial Phase II & {$[108]$} \\
\hline \multirow[t]{2}{*}{ Gliomas } & 13-cis-RA & Trial Phase III & [109] \\
\hline & Fenretinide & Trial Phase II & [110] \\
\hline Hepatocellular carcinoma & Polyprenoic acid & Observational study & [111] \\
\hline Mantle cell lymphoma & Fenretinide & Trial Phase II & [102] \\
\hline \multirow[t]{2}{*}{ Medulloblastoma } & Fenretinide & Trial Phase I & {$[106]$} \\
\hline & 13-cis-RA & Observational study & {$[107]$} \\
\hline Multiple myeloma & ATRA & Trial Phase II & {$[112]$} \\
\hline \multirow[t]{3}{*}{ Neuroblastoma } & 13-cis-RA & Observational study & {$[107]$} \\
\hline & & Trial Phase I & {$[9]$} \\
\hline & Fenretinide & Trial Phase I & [106] \\
\hline Non-small lung cancer & ATRA & Trial Phase II & [113] \\
\hline \multirow[t]{2}{*}{ Osteosarcoma } & 13-cis-RA & Observational study & [107] \\
\hline & Fenretinide & Trial Phase I & {$[106]$} \\
\hline Ovarian carcinoma & Fenretinide & Trial Phase II & [114] \\
\hline Pancreatic carcinoma & ATRA & Trial Phase I & [115] \\
\hline Papillary thyroid cancer & 13-cis-RA & Observational study & [116] \\
\hline Prostate carcinoma & Fenretinide & Trial Phase II & {$[117]$} \\
\hline Renal carcinoma & Fenretinide & Trial Phase II & [118] \\
\hline Small cell lung cancer & Fenretinide & Trial Phase II & [119] \\
\hline Squamous cell carcinoma & 13-cis-RA & Case series trial & [120] \\
\hline T-cell malignancies & 13-cis-RA & Phase II & {$[121]$} \\
\hline Wilm's tumor & Fenretinide & Phase I & {$[106]$} \\
\hline
\end{tabular}


cancer treatment, especially due to its pro-apoptotic and anti-angiogenic effects even in ATRA-resistant cell lines and with minor side-effects profile [10]. Bexarotene is a synthetic retinoid that is approved by the European Medicines Agency to treat skin manifestations of advanced-stage cutaneous T-cell lymphoma in adult patients refractory to at least one systemic treatment [11]. Several studies have suggested that bexarotene is an effective anticancer treatment that is able to decrease proliferation and promote apoptosis in cells expressing retinoid X receptors (RXRs) [12, 13]. A very recent study described synthesis of a novel retinoid WYC-209, which abrogates growth of melanoma tumor-repopulating cells and inhibits lung metastases in vivo, showing minimal toxicity on non-tumor cells [14].

When it comes to synthetic RA analogues that are still being synthesized and tested, the biggest disadvantage of such new compounds is undoubtedly the lack of information about their long-term effects on human body.

\section{Mechanisms of retinoid resistance}

Biological retinoid activity is based on the binding of retinoids to specific nuclear receptors (retinoic acid receptors (RARs) bind retinoic acid and RXRs bind retinoids) that act as inducible transcription factors. When activated, these nuclear receptors form RXR-RAR heterodimers or RXR-RXR/RAR-RAR homodimers that subsequently modulate retinoid-responsive gene expression two ways: (i) by binding to retinoic acid response elements (RAREs) in the promoter regions of target genes or (ii) by antagonizing the enhancer action of other transcription factors, such as AP1 or NF-IL6 [15].

Although pharmacological retinoid doses have been approved by the Food and Drug Administration (FDA) and other regulatory bodies for the treatment of some hematologic malignancies and high-risk NBL, the chemopreventive and therapeutic effects of retinoids in other solid tumors are still unclear. Even in tumors that are treated with retinoids the therapeutic response to the retinoids is often limited to a small proportion of the treated patients [16]. This limited effect is thought to result from retinoid resistance, which is defined as the lack of a tumor cell response to the same pharmacological dose of retinoids that sensitive cells respond to, as evidenced by proliferation arrest or differentiation. Moreover, after retinoid treatment, some carcinomas not only fail to exhibit growth inhibition but instead respond with enhanced proliferation. A clue to this paradoxical behavior was suggested by the finding that retinoic acid and its natural receptor also activate peroxisome proliferator-activated receptor (PPAR) $\beta$ and $\delta(\operatorname{PPAR} \beta / \delta)$, which are involved in mitogenic and anti-apoptotic activities [17].

Many potential mechanisms have been proposed for retinoid resistance (Fig. 1). In general, the cancer cell response to the pharmacological retinoid doses is affected by several mechanisms, including decreased retinoid uptake [18], increased retinoid catabolism by cytochrome P450 [19], active drug efflux by membrane transporters, the downregulated expression of various RAR genes (promoter methylation), the altered expression of coactivators or downstream target genes, and changes in the activities of other signaling pathways [20].

Although retinoid resistance remains problematic in the area of biological anticancer therapy, the discovery of biomarkers that indicate retinoid resistance or sensitivity in each individual patient seems to be important for the recent personalized therapy strategy, which is aimed at identifying of the most effective therapy for individual patients. In the next chapters, we focus on describing the most promising putative biomarkers that predict retinoid resistance or sensitivity in the most relevant cancer types.

\section{Predictive biomarkers of retinoid resistance}

During the past decades, several biomarkers have been identified that can predict the therapeutic response to retinoid treatment in a few human malignancies, including adult leukemia, pancreatic and breast carcinoma and pediatric NBL. These predictive biomarkers are both genetic alterations (typically chromosomal translocations leading to fusion protein expression) and proteins (upregulated or downregulated). In the following parts of this review, we present the recent knowledge concerning these biomarkers in relation to retinoid resistance and sensitivity. An overview of all these biomarkers is given in the Table 2 .

\section{Predictive biomarkers in acute myeloid leukemia}

Acute myeloid leukemia (AML) is a heterogenous malignant clonal disease characterized by the accumulation of undifferentiated myeloid blasts, which predisposes patients, especially those with APL-type AML, to overcome impaired differentiation via differentiation-inducing agents, such as granulocyte-colony stimulating factor (GCSF) or ATRA, in addition to conventional chemotherapy [21, 22]. Despite providing high cure rates, such approach is associated with hematologic toxicity as well as with the risk of secondary myeloid neoplasms in approximately $2 \%$ of patients. The introduction of arsenic trioxide (ATO) and especially the studies on combined treatment with ATRA plus ATO showed the possibility how to improve the effectiveness of ATRA in APL patients: two large independent randomized trials reported significant improvement in clinical outcome of patients treated with ATRA-ATO if compared with those receiving ATRA only [23, 24].

Studies from the last decade identified meningioma 1 (MN1) as a hematopoietic oncogene with a key role in myeloid leukemogenesis. Based on the gene expression analyses in several hundreds of AML patients, MN1 overexpression is associated with a poor prognosis in these patients [25-27]. 


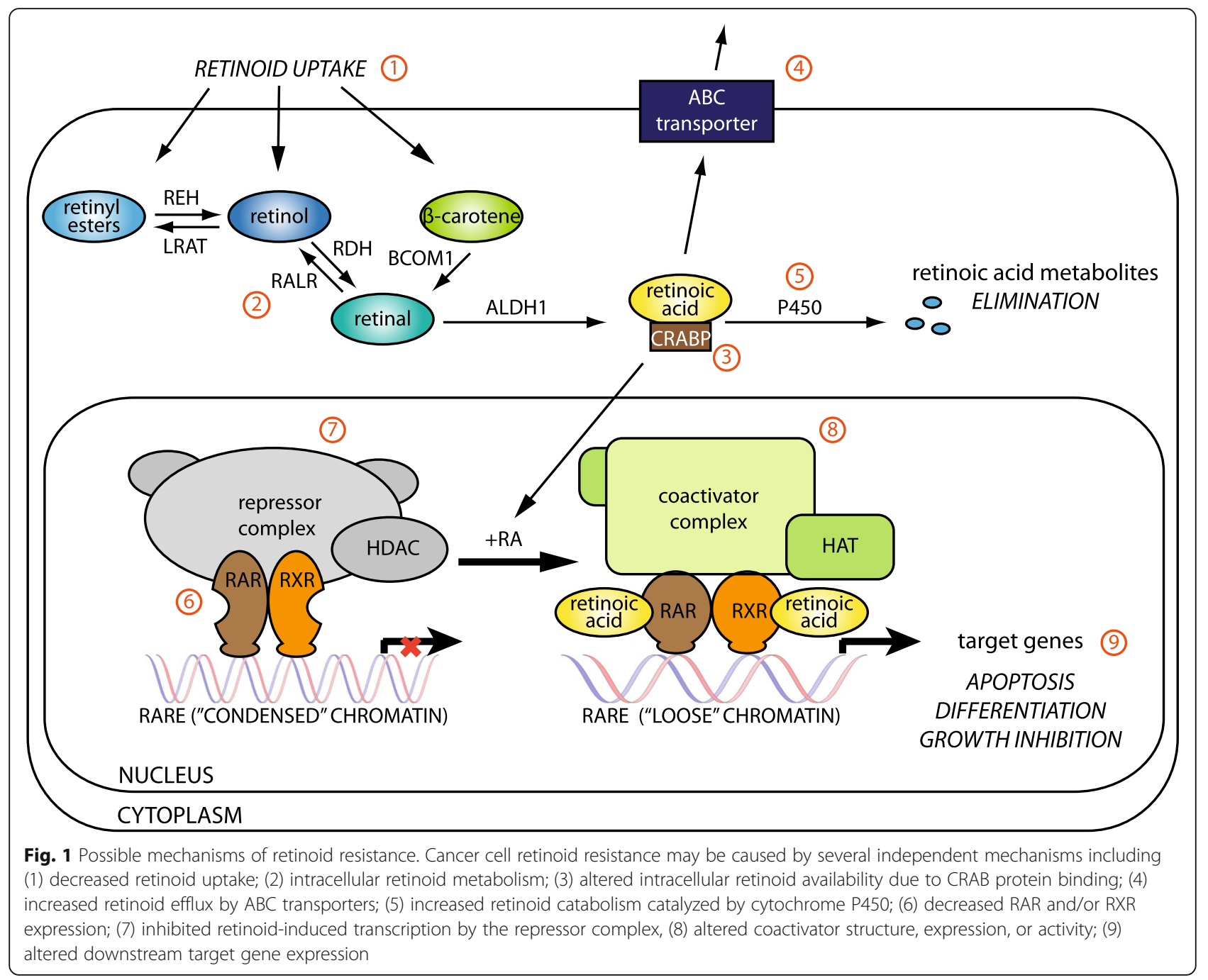

Specifically, 67.4\% AML patients had high levels of MN1 expression if compared with control group and $75 \%$ of AML patients with high $M N 1$ expression were classified as of intermediate risk according cytogenetic risk categories [27]. The MN1 protein seems to have at least two functions: promote self-renewal and proliferation and block cell differentiation [28]. Interestingly, MN1 locates to RAREs and has been implicated as a transcription cofactor in RAR-RXR-mediated transcription [29]. A study on the MN1 expression pattern in AML patients revealed that MN1 overexpression is strongly associated with resistance to ATRA-induced differentiation and cell cycle arrest. In MN1-overexpressing hematopoietic cells, several genes regulated by RAR $\alpha(p 21, p 27)$ were repressed and were not upregulated by ATRA treatment [28].

APL is also characterized by a specific chromosomal translocation (Fig. 2a) between the retinoic acid receptor alpha $(R A R A)$ and a number of fusion partners $(X-R A R A)$. This chromosomal rearrangement plays a critical role in the disease phenotype, particularly regarding ATRA sensitivity.
Although a high proportion of APL patients achieve complete remission after treatment with ATRA, most patients who receive continuous ATRA treatment later relapse and develop the ATRA-resistant phenotype of this disease [30]. At least $98 \%$ of APL patients carry the $t(15 ; 17)$ translocation, resulting in $R A R A$ fusion with the promyelocytic leukemia $(P M L)$ gene (PML-RARA) [31]. The fusion of $P M L$ sequences to $R A R A$ regions increases fusion receptor affinity for co-repressors [32]. Therefore, the increased levels of ATRA are required to induce dissociation of co-repressors and to promote a therapeutic response to the treatment. In addition to $P M L$, a limited number of patients exhibit a variety of other $X$-RARA fusions [33-39]. The fusion partner also plays a key role in the response to the retinoid treatment: APL patients carrying NPM1 and $N u M A$ fusion partners respond clinically to ATRA treatment [40, 41], whereas APL cases involving PLZF (promyelocytic leukemia zinc finger), IRF2BP2 (interferon regulatory protein 2 binding protein 2) and $S T A T 5 b$ presented with ATRA resistance and a poor prognosis [42-45]. One of the 
Table 2 Overview of the candidate biomarkers for predicting the retinoid treatment response in various human malignancies

\begin{tabular}{|c|c|c|c|}
\hline Putative predictive biomarker & $\begin{array}{l}\text { Tumor } \\
\text { type }\end{array}$ & Experimental model & Reference \\
\hline \multicolumn{4}{|l|}{ Biomarkers indicating retinoid resistance } \\
\hline MN1 overexpression & AML & 83 newly diagnosed patients (60 years or older) treated in the trial NCT00151255 & [28] \\
\hline PML-RARA expression & APL & NB4 cell line & [32] \\
\hline PLZF-RARA+RARA-PLZF expression & APL & $\begin{array}{l}\text { Case reports of } 6 \text { patients with PLZF-RARA fusion genes with no clinically signifi- } \\
\text { cant response to ATRA }\end{array}$ & [42] \\
\hline IRF2BP2-RARA expression & APL & Case report of 1 patient resistant to ATRA & [44] \\
\hline STAT5b-RARA expression & APL & Case report of 1 patient resistant to ATRA & [43] \\
\hline $\begin{array}{l}\text { PML L-type splicing variant in E5(-)E6(-) } \\
\text { isoform }\end{array}$ & APL & Short report of 79 de novo patients & [57] \\
\hline $\begin{array}{l}\text { PML V-type splicing variant with spacer } \\
\text { between PML-RARA }\end{array}$ & APL & Sequence analysis of RARa genomic region of 3 patients & [61] \\
\hline \multirow[t]{2}{*}{ FABP5 overexpression } & PDAC & 14 patient-derived cell lines & [71] \\
\hline & $\mathrm{BC}$ & MCF-7 cell line & [17] \\
\hline Truncated RAR $\beta^{\prime}$ isoform expression & $B C$ & MCF-7 cell line & [78] \\
\hline ERBB2 expression & $\mathrm{BC}$ & MCF-7 and HER2/NEU transfected MCF-7 cell lines & [79] \\
\hline CRABP1 expression & $B C$ & FFPE breast tumor tissue samples, established cell lines & [81] \\
\hline CRABP2 knockdown & PDAC & 14 patient-derived cell lines & [71] \\
\hline NF1 knockdown & NBL & Panel of 25 cell lines & [91] \\
\hline HMGA2 expression & NBL & 4 established cell lines & [96] \\
\hline UNC45 expression & NBL & F9 mouse embryo teratocarcinoma cell line & [100] \\
\hline \multicolumn{4}{|l|}{ Biomarkers indicating retinoid sensitivity } \\
\hline NuMA-RARA expression & APL & Frozen bone marrow samples & [40] \\
\hline NPM1-RARA expression & APL & Cultured bone marrow cells from patient harvested at time of relapse & [41] \\
\hline PLZF-RARA expression & APL & Case report of 62-year-old patient & [54] \\
\hline RARa receptor overexpression & $\mathrm{BC}$ & $\begin{array}{l}2 \text { established cell lines, tissue cultures of primary breast tumors, } 42 \text { established cell } \\
\text { lines }\end{array}$ & {$[76,77]$} \\
\hline ZNF423 expression & NBL & Panel of 25 cell lines & [91] \\
\hline PBX1 expression & NBL & $\begin{array}{l}16 \text { established cell lines, } 3 \text { independent clinical datasets (ganglioneuromas } n=7 \text {, } \\
\text { low-risk NBL } n=11 \text {, intermediate-risk NBL } n=5 \text { ) }\end{array}$ & [88] \\
\hline HOXC9 expression & NBL & 3 established cell lines & [89] \\
\hline
\end{tabular}

$A M L$ acute myeloid leukemia, $A P L$ acute promyelocytic leukemia, $P D A C$ pancreatic ductal adenocarcinoma, $B C$ breast carcinoma, NBL neuroblastoma

most important tools in APL treatment is minimal residual disease monitoring with a special focus on the molecular detection of the PML-RARA transcript. Although the possibility of this monitoring was also reported in patients with PLZF-RARA- and STAT5b-RARA-positive diseases, no data regarding the clinical value of this tool are available [46, 47].

Molecular analysis of the possible mechanisms of retinoid resistance suggested that the reciprocal $R A R$ $A-P L Z F$ fusion product from the derivative chromosome 17 [der(17)] functions as a transcriptional activator targeting PLZF-binding sites, leading to cellular retinoic acid-binding protein 1 (CRABP1) upregulation. The CRABP1 protein is structurally similar to the cellular retinol-binding proteins, sequesters retinoic acid to limit its access to the nucleus [48], and is a well-established mediator of retinoid resistance in various biological models [49-51]. Similarly, APL patients expressing both fusion gene products exhibited primary resistance to ATRA $[42,52,53]$. In contrast, blast cells from a patient with the PLZF-RARA fusion transcript only were sensitive to ATRA treatment under in vitro conditions, and these results correlated with clinical remission after ATRA administration in this patient [54]. Moreover, two fusion proteins, PLZF-RARA and RARA-PLZF, negatively impacted the activity of CCAAT/enhancer binding protein $\alpha(\mathrm{C} / \mathrm{EBP} \alpha)$, a master regulator of granulocytic differentiation [55]. Further research in a murine APL model demonstrated that the co-administration of 8-CPT-cAMP (8-chlorophenylthio-adenosine-3', 5'-cyclic monophosphate) improves the therapeutic effect of ATRA by enhancing cellular differentiation and increasing PLZF-RARA degradation [56]. Nevertheless, the 


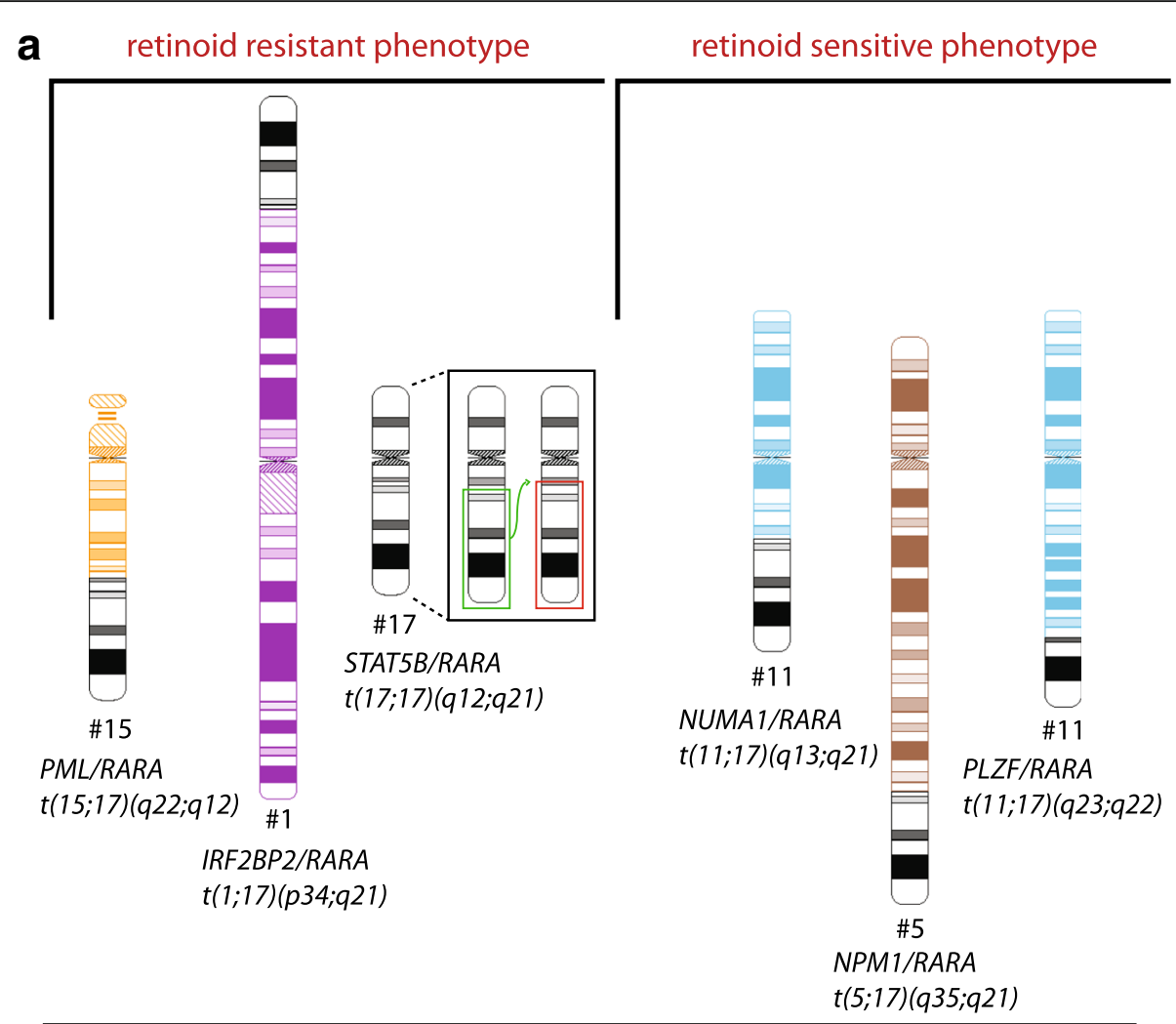

b $\quad P M L$ breakpoint cluster regions

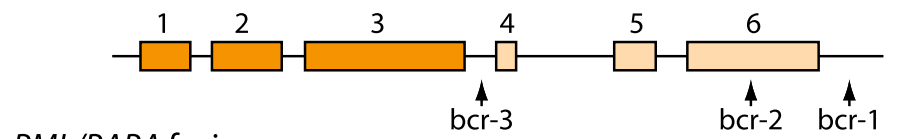

PML/RARA fusion gene

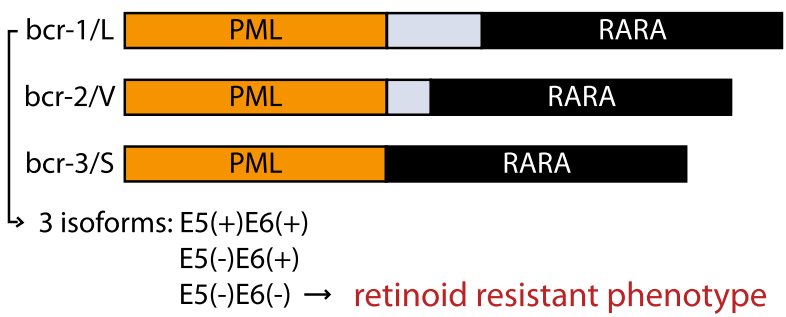

Fig. 2 Genetic alterations used as predictive biomarkers for APL patients. a Chromosomal translocations between RARA and several fusion partners playing an important role in maintaining resistance/sensitivity of APL patients to retinoids [122]. b Breakpoint cluster regions (bcr) in PML gene resulting in alternative splicing and different therapeutic response to ATRA in APL patients. E5(-)E6(-) isoform of L-type fusion transcript with exons 5 and 6 deleted is associated with the ATRA-resistant phenotype

ability of this type of combined differentiation therapy to overcome retinoid resistance has never been proven in humans.

Published results on APL cell lines also suggest a possible association between the splicing variants of the PML-RARA fusion gene and the therapeutic response to ATRA [57]. These variants resulted from the alternative splicing of the $P M L$ sequence, which contains heterogeneous breakpoint cluster regions (bcrs) at three different sites (Fig. 2b) [58-60].
Sequencing analysis of the $P M L-R A R A$ gene in a cohort of 79 APL patients showed that the L-type fusion transcript resulting from the alternative splicing was present in three isoforms. One of these isoforms, the E5(-)E6(-) isoform with exons 5 and 6 deleted, is associated with the ATRA-resistant phenotype [57]. A subsequent localization study reported that the E5(-)E6(-) protein was detected in the cytoplasm only, whereas the other two isoforms were distributed throughout the nucleus and cytoplasm. The exclusive cytoplasmic localization of the E5(-)E6(-) isoform 
is apparently responsible for inhibiting ATRA-dependent transcription and for subsequently blocking cell differentiation. Thus, monitoring E5(-)E6(-) isoform expression in APL patients with the L-type PML-RARA fusion gene might be helpful for predicting a patient's response to ATRA treatment.

Similarly, APL cells with the V-type splicing isoform, characterized by exon 6 truncation, were also reported to be less sensitive to ATRA treatment. In this group of APL patients, a subset with lower ATRA sensitivity presented with a relatively long "spacer" with a cryptic coding sequence inserted into the joining sites between the truncated PML and RARA mRNA fusion partners. Subsequent in vitro studies confirmed these results, revealing that spacer deletion restored ATRA sensitivity [61].

\section{Predictive biomarkers in pancreatic ductal adenocarcinoma}

The vitamin A metabolism disturbances that result in a decreased intracellular ATRA concentration were originally described in pancreatic ductal adenocarcinoma (PDAC) [62] and later, in other human malignancies, also [63]. Previous studies in PDAC cell lines have indicated the ability of ATRA to induce cell cycle arrest and differentiation, although these data revealed highly variable retinoid sensitivity among the PDAC cell lines [64, 65]. Based on the receptor-dependent retinoid mechanism, the potential patient benefit from this treatment is highly dependent on the retinoid receptor expression level in tumor tissue. Among others, RAR $\beta$ expression is downregulated in PDAC [66-68], which may explain the negative outcomes of clinical trials focused on retinoid treatments.

ATRA typically induces cell differentiation and growth arrest in most epithelial cell types. However, experiments in Capan-1 cell line have shown that in addition to an antiproliferative effect, retinoids increase cell migration, resulting in an invasive phenotype [69]. This effect is probably caused by the presence of the nuclear receptors $\operatorname{PPAR} \beta / \delta$, which are also activated by exogenous retinoids and form heterodimers with RXR. While canonical RAR-dependent gene expression leads to growth arrest, PPAR $\beta / \delta$ activation initiates proliferation, cell survival and tumor growth in mouse model [70]. The distribution of available ATRA between $\mathrm{PPAR} \beta / \delta$ and RAR receptors is regulated by the levels of two key intracellular ligand-binding proteins: fatty acid-binding protein 5 (FABP5) and cellular retinoic acid-binding protein 2 (CRABP2). Depending on their relative abundance within the cell, FABP5 and CRABP2 transport exogenous retinoids from the cell cytoplasm into the nucleus, to either PPAR $\beta / \delta$ or RARs [17]. A recent study on 14 PDAC cell lines demonstrated that it might be possible to predict PDAC cell sensitivity to ATRA on the basis of the relative expression levels of these two retinoid-binding proteins. According to this study, 10 of 14 cell lines expressed the one or the other binding protein confirming the pattern of reciprocal differential expression of both transcripts in PDAC cells. FABP $5^{\text {high }} C R A B P 2^{\text {null }}$ PDAC lines were resistant to ATRA-mediated growth inhibition and apoptosis and also exhibited an increased migration and invasion phenotype. In contrast, $\mathrm{FABP} 5^{\text {null }} \mathrm{CRABP} 2^{\text {high }}$ cell lines retained ATRA sensitivity. These results were also confirmed in vivo using xenograft models [71]. Immunohistochemical detection of FABP5 in PDAC samples revealed that about $20 \%$ of them were completely negative for FABP5 indicating these patients as suitable candidates for retinoid therapy [71]. Since the retinoid binding affinity of the CRABP2-RAR pathway is higher than that of the FABP5-PPAR $\beta / \delta$ pathway, at least a partial ATRA-mediated tumor-suppressive effect is expected in tumors with comparable FABP5 and CRABP2 expression.

\section{Predictive biomarkers in breast carcinoma}

Breast carcinoma is a heterogenous disease classified into subtypes according to the expression of biological markers, such as estrogen receptor (ER), progesterone receptor (PR) and epidermal growth factor receptor 2 (HER2) [72-74]. According to recent clinical trials aimed at investigating the efficacy of retinoids as adjuvant treatment in breast carcinoma, some patients benefited from the retinoid treatment. Moreover, the breast carcinoma cell response to retinoids can be predicted by evaluating the expression of several marker proteins.

Indeed, several studies have demonstrated that the average RAR $\alpha$ receptor level is significantly higher in ATRA-sensitive than ATRA-resistant breast carcinoma cell lines [75-77]. Furthermore, a truncated RAR $\beta$ ' isoform has also been identified in some of these cell lines and it has been associated with increased cell proliferation and ATRA resistance [78].

Another potential marker of ATRA resistance was suggested by a study describing Her2/neu-induced ATRA resistance in breast cancer cell lines [79]. ERBB2 transfection in ATRA-sensitive breast carcinoma cells induced ATRA resistance. When Her2/neu was blocked by trastuzumab, the cells exhibiting induced ATRA resistance became ATRA sensitive again. This study also hypothesized that Her2/neu may induce ATRA resistance in breast carcinoma cells by suppressing RARA expression and/or by deregulating the G1 checkpoint of the cell cycle.

As described in the PDAC section in this review, the abundance of the intracellular retinoic acid transporters CRABP2 and FABP5 within the cell can indicate breast carcinoma cell response to ATRA, since these molecules have been shown to play opposing roles in mediating the cellular response to retinoids [17]. According to the microarray analysis of gene expression in 176 primary breast carcinoma samples, FABP5 is preferentially upregulated in estrogen receptor-negative (ER-) and triple-negative breast 
carcinoma cells (TNBC), and an increased FABP5 mRNA level is associated with poor patient prognosis and high tumor grade [80]. In this study, FABP5 normalized signal intensity scores were categorized into high versus low using cut-off point of 0.768 . In this cohort, $61 \%$ of patients showed high FABP5 expression and these patients had a significantly decreased survival rate if compared with those with low FABP5 expression. Moreover, FABP5 silencing in Hs578T breast carcinoma cell line resulted in approximately $40 \%$ reduction in proliferation activity. However, although breast cancer cells with an increased FABP5/ CRABP2 ratio present with increased ATRA resistance, this ratio does not always accurately predict the breast cancer cell response to ATRA, indicating that other factors are also involved in the mechanism of retinoid resistance development. Another recent study identified CRABP1 as the third key player that potentially influences the breast cancer cell response to ATRA. This protein has been identified as a retinoid inhibitor and probably sequesters retinoic acid in the cytoplasm, thereby preventing RAR activation in the nucleus. Similarly to FABP5, CRABP1 is also preferentially expressed in ER- and TNBC tumor tissues that are prone to ATRA resistance [81]. According to this study, CRABP1 synergizes with FABP5 to compete with CRABP2 for retinoic acid molecules, thereby reducing retinoic acid access to RARs within the nucleus.

These findings provide molecular tools to predict and eventually overcome ATRA resistance in breast carcinoma therapy. CRABP1 and FABP5 co-expression may serve as a predictive biomarker of ATRA resistance in this tumor type, and the downregulation may be a key step in (re)sensitizing breast carcinoma cells to retinoid therapy. A novel mechanism for resensitizing ATRA-resistant cells to ATRA-mediated apoptosis was recently introduced: the phytochemical curcumin is able to upregulate CRABPII, RAR $\beta$ and RAR $\gamma$ expression in TNBC cell lines and thereby sensitizes cells to ATRA-induced apoptosis. This reversed resistance to ATRA-induced apoptosis in TNBC cells was dependent on the curcumin dose and treatment length [82]. Overall, this study highlights the potential of curcumin as a possible therapeutic adjuvant in ATRA-resistant breast carcinomas.

Another recent study compared the phosphoproteome and transcriptome of established ATRA-sensitive and ATRA-resistant cell lines derived from breast carcinoma (MCF7, BT474). One of the most interesting results was that ATRA did not regulate the phosphorylation of the same proteins in both cell lines, i.e., the ATRA-resistant cell line exhibited a deregulated kinome. High-throughput sequencing experiments revealed that $80 \%$ of the genes regulated by ATRA in MCF7 cells were not regulated in BT474 cells and vice versa. Additionally, 40\% more genes were regulated by ATRA in the MCF7 cells than in the BT474 cells. Moreover, this study indicates that ATRA induced RAR $\alpha$ phosphorylation in resistant cell lines only, which may cause kinome deregulation and consequences in other intracellular metabolic pathways [83].

\section{Predictive biomarkers in neuroblastoma}

Neuroblastoma (NBL) is a neuroectodermal tumor arising from elements of the neural crest and represents the most common extracranial solid tumor in children. In a subset of high-risk NBL patients with minimal residual disease, retinoid administration was proven effective as a part of postconsolidation therapy after intensive multimodal treatment. Unfortunately, approximately $50 \%$ of this patient population is resistant to this treatment or develops resistance during therapy [84]. Moreover, a recent study evaluated the efficacy and safety of additional retinoid therapy in NBL patients and presented a more critical view, concluding that no clear evidence exists for a difference in overall survival and event-free survival in patients with high-risk NBL treated with or without retinoids [85]. However, the usefulness of differentiation therapy with retinoids largely depends on the ability to identify a subset of NBL patients who benefit from this treatment, according to analyses of retinoid resistance/ sensitivity markers. Recent investigations on the mechanisms of retinoid resistance identified several downstream retinoid-regulated proteins and discussed these proteins as possible predictive biomarkers for the clinical response to retinoid treatment.

PBX1 belongs to the three-amino-acid loop extension (TALE) family of atypical homeodomain proteins and interacts with other homeodomain-containing nuclear proteins, such as HOX and MEIS, to form heterodimeric transcription complexes. PBX1 is involved in a variety of biological processes including cell differentiation and tumorigenesis [86, 87]. Recent study revealed that in NBL cell lines treated with 13-cis-RA, PBX1 mRNA and protein expression levels are both induced in 13-cis-RA-sensitive cell lines only. After treatment with 13-cis RA, all 6 RA-sensitive cell lines showed a significant increase in PBX1 expression, whereas RA-resistant cell lines exhibited no such effect. These studies also revealed that reduced PBX1 protein levels result in an aggressive growth phenotype and 13-cis-RA resistance. Finally, the authors demonstrated that in primary NBL tumor tissue, PBX1 expression correlated with the histological NBL subtype, with the highest PBX1 expression in benign ganglioneuromas and the lowest expression in high-risk NBL [88].

Homeobox (HOX) proteins function as regulators of morphogenesis and cell fate specification and are key mediators of retinoid action in nervous system development. Among members of the HOX family of transcription factors, HOXC9 seems to play an important role in neuronal differentiation. A recent study revealed that 
the HOXC9 promoter is epigenetically primed in an active state in ATRA-sensitive NBL cell lines and in a silenced state in ATRA-resistant NBL cell lines. Moreover, HOXC9 protein levels were significantly higher in differentiated NBL cells than in NBL cells undergoing ATRA-induced differentiation [89].

The protein neurofibromin 1 (NF1) is known to antagonize the activation of RAS proteins but is also involved in other signaling pathways, such as the cAMP/ PKA pathway [90]. NF1 controls the retinoid treatment response in NBL cells through the RAS-MEK signaling cascade and has been identified as the lead candidate gene for influencing retinoic acid-induced differentiation in NBL cell models [91]. According to this study, SH-SY5Y cells with NF1 knockdown continued to proliferate when exposed to RA in contrast to the control cells. Subsequent experiments showed downregulation of RA target genes in NF1 knockdown cells. These results may indicate the role of NF1 in maintaining RA resistant phenotype.

In further research, genomic aberrations of the NF1 gene were found in $6 \%$ of primary NBL representing a subset of cases where the loss of NF1 gene could be caused by gene mutation.

A connection between NF1-RAS-MEK signaling and retinoic acid action was demonstrated by the finding that the NF1-RAS-MEK cascade suppresses ZNF423 protein expression, which functions as a RAR/RXR coactivator. Additionally, tumors with activated RAS signaling and low ZNF423 expression present with a poor response to 13-cis-RA (isotretinoin) treatment. Moreover, decreased NF1 and ZNF423 gene expression, reflecting hyperactivated RAS/MAPK signaling, is correlated with a very poor clinical outcome in NBL patients and was detected in $78 \%$ of patients with relapsed NBL [92], whereas high expression levels both of these proteins are associated with the best prognosis in NBL patients. As a result, Holzel and colleagues suggest that pharmacological MEK inhibition can sensitize NBL cells that are resistant to retinoid-induced terminal differentiation. Although these data seem to be readily translatable, several important questions will need to be addressed before incorporating this therapy into clinical practice. It will be critically important to determine how MEK inhibition combined with isotretinoin will fit into the overall NBL treatment strategy and whether MAPK pathway activation is a mechanism of acquired resistance to isotretinoin therapy or a collateral event of oncogenic driver mutations only [93]. Another recent study also indicated a potential role of MEK cascade inhibition in overcoming ATRA resistance in malignant peripheral nerve sheath tumors (MPNST) in vitro, but no correlation was found between ZNF423 mRNA levels and the sensitivity of MPNST cells to ATRA [94]. These results demonstrate that some other mechanisms are involved in maintaining ATRA resistance of MPNSTS cells.
High-mobility group A (HMGA) proteins function as ancillary transcription factors and regulate gene expression through direct DNA binding or protein-protein interactions and play important functions in controlling cell growth and differentiation. HMGA2 is completely absent in adult organisms; its expression is restricted to rapidly dividing embryonic cells and tumors with epithelial and mesenchymal origins [95]. HMGA2 was also detected in some retinoid-resistant NBL cell lines. In NBL cell lines, a causal link between HMGA2 expression and retinoid-induced growth arrest inhibition was proven using exogenous HMGA2 expression, which was sufficient to convert HMGA2-negative, retinoid-sensitive cells into retinoid-resistant cells [96]. In contrast, HMGA1 was found to be expressed at different levels in all NBL cell lines [97], indicating that its action is necessary for functions conserved throughout the developmental differentiation of the sympathetic system.

UNC45A, another potential marker of retinoid resistance, is a protein encoded by the UNC45A gene, a member of UNC45-like genes, which are evolutionarily highly conserved, and the resulting protein products are involved in muscle development and myosin assembly [98]. The UNC45A protein has been shown to modulate the HSP90-mediated molecular chaperoning of the progesterone receptor, since the UNC45A blocks the chaperoning of this receptor to the hormone-binding state [99]. In NBL cell lines, the role of UNC45A in causing ATRA resistance was suggested by Epping and co-workers [100]. When UNC45A was ectopically expressed in their experiments, ATRA-sensitive human NBL cell lines failed to undergo growth arrest after ATRA treatment. The UNC45A protein levels required for ATRA resistance were similar to the levels in several cancer cell lines. Neither the endogenous nor the ectopically expressed UNC45A protein levels were affected by ATRA treatment. Moreover, UNC45A expression also inhibited the differentiation of NBL cells cultured in the presence of ATRA, indicating the resistant phenotype.

\section{Conclusion}

This review was aimed to summarize the current knowledge, both clinical and experimental, on predictive markers in human cancers that are treated with retinoids as a part of the therapeutic regimen. This review demonstrated that each described cancer type seems to have a unique pattern of altered signaling pathways, resulting in a set of predictive biomarkers that indicate retinoid resistance or sensitivity, which is typical for this malignancy. Many of the research studies mentioned in this review are only initial, and the acquired results require further detailed 
investigation and clinical validation of the proposed predictive biomarkers. However, these studies demonstrate the promising future for differentiation therapies that use retinoids, especially in identifying reliable markers that predict the response of each individual patient to this type of treatment. Hopefully, the personalized approach will be a new milestone in anticancer differentiation therapy.

\section{Abbreviations}

13-cis-RA: 13-cis retinoic acid; 4-HPR: Fenretinide (N-(4-hydroxyphenyl) retinamide); 8-CPT-CAMP: 8-chlorophenylthio-adenosine-3', 5'-cyclic monophosphate; 9-cis-RA: 9-cis retinoic acid; AML: Acute myeloid leukemia; APL: Acute promyelocytic leukemia; ATO: Arsenic trioxide; ATRA: All-trans retinoic acid; $B C$ : Breast carcinoma; $B c r$ : Breakpoint cluster region; C/ EBPa: CCAAT/enhancer binding protein a; CRABP: Cellular retinoic acidbinding protein; ER: Estrogen receptor; FABP5: Fatty acid-binding protein 5; FDA: Food and Drug Administration; GCSF: Granulocyte-colony stimulating factor; HER2: Epidermal growth factor receptor 2; HMGA: High-mobility group A; HOX: Homeobox; IRF2BP2: Interferon regulatory protein 2 binding protein 2; MN1: Meningioma 1; MPNST: Malignant peripheral nerve sheath tumor; NBL: Neuroblastoma; PDAC: Pancreatic ductal adenocarcinoma; PLZF: Promyelocytic leukemia zinc finger; PML: Promyelocytic leukemia; PPAR: Peroxisome proliferator-activated receptor; PR: Progesterone receptor RAR: Retinoic acid receptor; RARE: Retinoic acid response elements; RXR: Retinoid X receptor; TALE: Three-amino-acid loop extension; TNBC: Triple-negative breast cancer

\section{Acknowledgements}

The authors thank Dr. Jan Skoda for the critical revision of the figures and his helpful comments.

\section{Funding}

This study was supported by project AZV MZCR 15-34621A and by project No. LQ1605 from the National Program of Sustainability II (MEYS CR).

\section{Availability of data and materials}

Not applicable.

\section{Authors' contributions}

VD and RV conceived and composed this review. PC, PM and JS critically edited and commented the draft versions of this manuscript. PC designed and drew the figures. All authors reviewed and approved the final version of the manuscript.

\section{Ethics approval and consent to participate}

Not applicable.

\section{Consent for publication}

Not applicable.

\section{Competing interests}

The authors declare that they have no competing interests.

\section{Publisher's Note}

Springer Nature remains neutral with regard to jurisdictional claims in published maps and institutional affiliations.

\section{Author details}

'Laboratory of Tumor Biology, Department of Experimental Biology, Faculty of Science, Masaryk University, Kotlarska 2, 61137 Brno, Czech Republic. ${ }^{2}$ International Clinical Research Center, St. Anne's University Hospital, Pekarska 53, 65691 Brno, Czech Republic. ${ }^{3}$ Department of Pediatric Oncology, University Hospital Brno and Faculty of Medicine, Masaryk University, Cernopolni 9, 61300 Brno, Czech Republic.
Received: 1 March 2018 Accepted: 17 October 2018

Published online: 01 November 2018

\section{References}

1. Nowak D, Stewart D, Koeffler HP. Differentiation therapy of leukemia: 3 decades of development. Blood. 2009;113:3655-65.

2. Koeffler HP. Induction of differentiation of human acute myelogenous leukemia cells: therapeutic implications. Blood. 1983;62:709-21.

3. Dragnev KH, Rigas JR, Dmitrovsky E. The Retinoids and cancer prevention mechanisms. Oncologist. 2000;5:361-8.

4. Sakashita A, Kizaki M, Pakkala S, Schiller G, Tsuruoka N, Tomosaki R, et al. 9-cis-retinoic acid: effects on normal and leukemic hematopoiesis in vitro. Blood. 1993;81:1009-16.

5. Khan AA, Villablanca JG, Reynolds CP, Avramis VI. Pharmacokinetic studies of 13-cis-retinoic acid in pediatric patients with neuroblastoma following bone marrow transplantation. Cancer Chemother Pharmacol. 1996;39:34-41.

6. Van Heusden J, Wouters W, Ramaekers FC, Krekels MD, Dillen L, Borgers M, et al. All-trans-retinoic acid metabolites significantly inhibit the proliferation of MCF-7 human breast cancer cells in vitro. Br J Cancer. 1998;77:26-32.

7. Reynolds CP. Differentiating agents in pediatric malignancies: Retinoids in neuroblastoma. Curr Oncol Rep. 2000;2:511-8.

8. Hu J, Liu Y-F, Wu C-F, Xu F, Shen Z-X, Zhu Y-M, et al. Long-term efficacy and safety of all-trans retinoic acid/arsenic trioxide-based therapy in newly diagnosed acute promyelocytic leukemia. Proc Natl Acad Sci U S A. 2009; 106:3342-7

9. Villablanca JG, Khan AA, Avramis VI, Seeger RC, Matthay KK, Ramsay NK, et al. Phase I trial of 13-cis-retinoic acid in children with neuroblastoma following bone marrow transplantation. J Clin Oncol. 1995;13:894-901.

10. Mittal N, Malpani S, Dyson M, Ono M, Coon JS, Kim JJ, et al. Fenretinide: a novel treatment for endometrial cancer. PLoS One. 2014;9:e110410.

11. Scarisbrick JJ, Morris S, Azurdia R, Illidge T, Parry E, Graham-Brown R, et al. U. $K$. consensus statement on safe clinical prescribing of bexarotene for patients with cutaneous T-cell lymphoma. Br J Dermatol. 2013;168:192-200.

12. Murakami K, Sakukawa R, Sano M, Hashimoto A, Shibata J, Yamada Y, et al. Inhibition of angiogenesis and intrahepatic growth of colon cancer by TAC101. Clin Cancer Res. 1999;5:2304-10.

13. Klopper J, Kane M, Jimeno A, Sams S, French J, Pike L, et al. A phase II trial of Bexarotene for advanced differentiated thyroid cancer. Thyroid. 2015:25:563-4

14. Chen J, Cao X, An Q, Zhang Y, Li K, Yao W, et al. Inhibition of cancer stem cell like cells by a synthetic retinoid. Nat Commun. 2018:9:1406.

15. Gigueere V. Retinoic acid receptors and cellular retinoid binding proteins: complex interplay in retinoid signaling. Endocr Rev. 1994;15:61-79.

16. Mongan NP, Gudas $\amalg$. Diverse actions of retinoid receptors in cancer prevention and treatment. Differentiation. 2007:75:853-70.

17. Schug T, Berry DC, Shaw NS, Travis SN, Noy N. Opposing effects of retinoic acid on cell growth result from alternate activation of two different nuclear receptors. Cell. 2007;129:723-33.

18. Moise AR, Noy N, Palczewski K, Blaner WS. Delivery of retinoid-based therapies to target tissues. Biochemistry. 2007:46:4449-58.

19. Su M, Alonso S, Jones JW, Yu J, Kane MA, Jones RJ, et al. All-trans retinoic acid activity in acute myeloid leukemia: role of cytochrome P450 enzyme expression by the microenvironment. PLoS One. 2015;10:e0127790.

20. Chlapek P, Slavikova V, Mazanek P, Sterba J, Veselska R. Why differentiation therapy sometimes fails: molecular mechanisms of resistance to Retinoids. Int J Mol Sci. 2018:19:132.

21. Belhabri A, Thomas X, Wattel E, Chelghoum Y, Anglaret B, Vekhoff A, et al. All trans retinoic acid in combination with intermediate-dose cytarabine and idarubicin in patients with relapsed or refractory non promyelocytic acute myeloid leukemia: a phase II randomized trial. Hematol J. 2002;3:49-55.

22. Milligan DW, Wheatley K, Littlewood T, Craig JIO, Burnett AK, NCR Haematological Oncology Clinical Studies Group. Fludarabine and cytosine are less effective than standard ADE chemotherapy in high-risk acute myeloid leukemia, and addition of G-CSF and ATRA are not beneficial: results of the MRC AML-HR randomized trial. Blood. 2006;107:4614-22.

23. Burnett AK, Russell NH, Hills RK, Bowen D, Kell J, Knapper S, et al. Arsenic trioxide and all-trans retinoic acid treatment for acute promyelocytic leukaemia in all risk groups (AML17): results of a randomised, controlled phase 3 trial. Lancet Oncol. 2015;16:1295-305. 
24. Lo-Coco F, Avvisati G, Vignetti M, Thiede C, Orlando SM, lacobelli S, et al 2013. Retinoic acid and arsenic trioxide for acute Promyelocytic leukemia 2013[WWW document].

25. Heuser M, Beutel G, Krauter J, Dohner K, von Neuhoff N, Schlegelberger B, et al. High meningioma 1 (MN1) expression as a predictor for poor outcome in acute myeloid leukemia with normal cytogenetics. Blood. 2006; 108:3898-905.

26. Xiang L, Li M, Liu Y, Cen J, Chen Z, Zhen X, et al. The clinical characteristics and prognostic significance of MN1 gene and MN1-associated microRNA expression in adult patients with de novo acute myeloid leukemia. Ann Hematol. 2013;92:1063-9.

27. Shafik RE, Hassan NM, Meligui YME, Shafik HE. The meningioma 1 (MN1) gene is an independent poor prognostic factor in adult Egyptian acute myeloid leukemia patients. Asian Pac J Cancer Prev. 2017;18:609-13.

28. Heuser M, Argiropoulos B, Kuchenbauer F, Yung E, Piper J, Fung S, et al. MN1 overexpression induces acute myeloid leukemia in mice and predicts ATRA resistance in patients with AML. Blood. 2007;110:1639-47.

29. van Wely KHM, Molijn AC, Buijs A, Meester-Smoor MA, Aarnoudse AJ, Hellemons A, et al. The MN1 oncoprotein synergizes with coactivators RAC3 and p300 in RAR-RXR-mediated transcription. Oncogene. 2003;22:699-709.

30. Warrell RP, de The H, Wang ZY, Degos L. Acute promyelocytic leukemia. N Engl J Med. 1993;329:177-89.

31. Rowley JD. Mapping of human chromosomal regions related to neoplasia: evidence from chromosomes 1 and 17. Proc Natl Acad Sci U S A. 1977;74: 5729-33.

32. de The H, Lavau C, Marchio A, Chomienne C, Degos L, Dejean A. The PMLRAR alpha fusion mRNA generated by the $t(15 ; 17)$ translocation in acute promyelocytic leukemia encodes a functionally altered RAR. Cell. 1991;66: 675-84.

33. Chen Z, Guidez F, Rousselot P, Agadir A, Chen SJ, Wang ZY, et al. PLZF-RAR alpha fusion proteins generated from the variant $t(11 ; 17)(q 23 ; q 21)$ translocation in acute promyelocytic leukemia inhibit ligand-dependent transactivation of wild-type retinoic acid receptors. Proc Natl Acad Sci U S A. 1994:91:1178-82.

34. Redner RL, Rush EA, Faas S, Rudert WA, Corey SJ. The t(5;17) variant of acute promyelocytic leukemia expresses a nucleophosmin-retinoic acid receptor fusion. Blood. 1996;87:882-6.

35. Wells RA, Catzavelos C, Kamel-Reid S. Fusion of retinoic acid receptor alpha to NuMA, the nuclear mitotic apparatus protein, by a variant translocation in acute promyelocytic leukaemia. Nat Genet. 1997;17:109-13.

36. Arnould C, Philippe C, Bourdon V, Gregoire MJ, Berger R, Jonveaux P. The signal transducer and activator of transcription STAT5b gene is a new partner of retinoic acid receptor alpha in acute promyelocytic-like leukaemia. Hum Mol Genet. 1999;8:1741-9.

37. Catalano A, Dawson MA, Somana K, Opat S, Schwarer A, Campbell LJ, et al. The PRKAR1A gene is fused to RARA in a new variant acute promyelocytic leukemia. Blood. 2007:110:4073-6.

38. Yamamoto $Y$, Tsuzuki S, Tsuzuki M, Handa K, Inaguma Y, Emi N. BCOR as a novel fusion partner of retinoic acid receptor alpha in a $t(X ; 17)(p 11 ; q 12)$ variant of acute promyelocytic leukemia. Blood. 2010;116:4274-83.

39. Yin CC, Jain N, Mehrotra M, Zhagn J, Protopopov A, Zuo Z, et al. Identification of a novel fusion gene, IRF2BP2-RARA, in acute promyelocytic leukemia. J Natl Compr Cancer Netw. 2015;13:19-22.

40. Chomienne C, Fenaux P, Degos L. Retinoid differentiation therapy in promyelocytic leukemia. FASEB J. 1996;10:1025-30.

41. Redner RL, Corey SJ, Rush EA. Differentiation of $t(5 ; 17)$ variant acute promyelocytic leukemic blasts by all-trans retinoic acid. Leukemia. 1997;11: 1014-6.

42. Licht JD, Chomienne C, Goy A, Chen A, Scott AA, Head DR, et al. Clinical and molecular characterization of a rare syndrome of acute promyelocytic leukemia associated with translocation (11;17). Blood. 1995;85:1083-94

43. Strehl S, Konig M, Boztug H, Cooper BW, Suzukawa K, Zhang SJ, et al. Alltrans retinoic acid and arsenic trioxide resistance of acute promyelocytic leukemia with the variant STAT5B-RARA fusion gene. Leukemia. 2013;27: 1606-10.

44. Shimomura $Y$, Mitsui $H$, Yamashita $Y$, Kamae $T$, Kanai A, Matsui $H$, et al. New variant of acute promyelocytic leukemia with IRF2BP2-RARA fusion. Cancer Sci. 2016;107:1165-8

45. Langabeer SE, Preston L, Kelly J, Goodyer M, Elhassadi E, Hayat A. Molecular profiling: a case of ZBTB16-RARA acute promyelocytic leukemia. Case Rep Hematol. 2017;2017:7657393.
46. Jovanovic JV, Rennie K, Culligan D, Peniket A, Lennard A, Harrison J, et al. Development of real-time quantitative polymerase chain reaction assays to track treatment response in retinoid resistant acute Promyelocytic leukemia. Front Oncol. 2011;1:35

47. De Angelis F, Breccia M. Molecular monitoring as a path to cure acute promyelocytic leukemia. Rare Cancers Ther. 2015;3:119-32.

48. Guidez F, Parks S, Wong H, Jovanovic JV, Mays A, Gilkes AF, et al. RARalphaPLZF overcomes PLZF-mediated repression of CRABPI, contributing to retinoid resistance in $\mathrm{t}(11 ; 17)$ acute promyelocytic leukemia. Proc Natl Acad Sci U S A. 2007;104:18694-9.

49. Dolle P, Ruberte E, Leroy P, Morriss-Kay G, Chambon P. Retinoic acid receptors and cellular retinoid binding proteins. I A systematic study of their differential pattern of transcription during mouse organogenesis. Development. 1990;110:1133-51.

50. Boylan JF, Gudas LJ. The level of CRABP-I expression influences the amounts and types of all-trans-retinoic acid metabolites in F9 teratocarcinoma stem cells. J Biol Chem. 1992;267:21486-91.

51. Pfoertner S, Goelden U, Hansen W, Toepfer T, Geffers R, Ukena SN, et al. Cellular retinoic acid binding protein I: expression and functional influence in renal cell carcinoma. Tumour Biol. 2005;26:313-23.

52. Guidez F, Huang W, Tong JH, Dubois C, Balitrand N, Waxman S, et al. Poor response to all-trans retinoic acid therapy in a t(11;17) PLZF/RAR alpha patient. Leukemia. 1994;8:312-7.

53. Koken MH, Daniel MT, Gianni M, Zelent A, Licht J, Buzyn A, et al. Retinoic acid, but not arsenic trioxide, degrades the PLZF/RARalpha fusion protein, without inducing terminal differentiation or apoptosis, in a RA-therapy resistant $\mathrm{t}(11 ; 17)(q 23 ; q 21)$ APL patient. Oncogene. 1999;18:1113-8.

54. Petti MC, Fazi F, Gentile M, Diverio D, De Fabritiis P, De Propris MS, et al. Complete remission through blast cell differentiation in PLZF/RARalphapositive acute promyelocytic leukemia: in vitro and in vivo studies. Blood. 2002;100:1065-7.

55. Girard N, Tremblay M, Humbert M, Grondin B, Haman A, Labrecque J, et al RARa-PLZF oncogene inhibits C/EBPa function in myeloid cells. Proc Natl Acad Sci U S A. 2013;110:13522-7.

56. Jiao B, Ren ZH, Liu P, Chen LJ, Shi JY, Dong Y, et al. 8-CPT-cAMP/all-trans retinoic acid targets $t(11 ; 17)$ acute promyelocytic leukemia through enhanced cell differentiation and PLZF/RARa degradation. Proc Natl Acad Sci U S A. 2013;110:3495-500.

57. Tan Y, Bian S, Xu Z, Chen X, Qi X, Ren F, et al. The short isoform of the longtype PML-RARA fusion gene in acute promyelocytic leukaemia lacks sensitivity to all-trans-retinoic acid. Br J Haematol. 2013;162:93-7.

58. Pandolfi PP, Alcalay M, Fagioli M, Zangrilli D, Mencarelli A, Diverio D, et al. Genomic variability and alternative splicing generate multiple PML/RAR alpha transcripts that encode aberrant PML proteins and PML/RAR alpha isoforms in acute promyelocytic leukaemia. EMBO J. 1992;11:1397-407.

59. Tong JH, Dong S, Geng JP, Huang W, Wang ZY, Sun GL, et al. Molecular rearrangements of the MYL gene in acute promyelocytic leukemia (APL, M3) define a breakpoint cluster region as well as some molecular variants. Oncogene. 1992;7:311-6.

60. Ruiz-Arguelles GJ, Garces-Eisele J, Reyes-Nunez V, Gomez-Rangel JD, RuizDelgado GJ. More on geographic hematology: the breakpoint cluster regions of the PML/RARalpha fusion gene in Mexican mestizo patients with promyelocytic leukemia are different from those in Caucasians. Leuk Lymphoma. 2004;45:1365-8.

61. Gu BW, Xiong H, Zhou Y, Chen B, Wang L, Dong S, et al. Variant-type PMLRAR(alpha) fusion transcript in acute promyelocytic leukemia: use of a cryptic coding sequence from intron 2 of the RAR(alpha) gene and identification of a new clinical subtype resistant to retinoic acid therapy. Proc Natl Acad Sci U S A. 2002;99:7640-5.

62. Bleul T, Ruhl R, Bulashevska S, Karakhanova S, Werner J, Bazhin AV. Reduced retinoids and retinoid receptors' expression in pancreatic cancer: a link to patient survival. Mol Carcinog. 2015;54:870-9.

63. Mira-Y-Lopez R, Zheng WL, Kuppumbatti YS, Rexer B, Jing Y, Ong DE. Retinol conversion to retinoic acid is impaired in breast cancer cell lines relative to normal cells. J Cell Physiol. 2000;185:302-9.

64. El-Metwally TH, Hussein MR, Pour PM, Kuszynski CA, Adrian TE. High concentrations of retinoids induce differentiation and late apoptosis in pancreatic cancer cells in vitro. Cancer Biol Ther. 2005:4:602-11.

65. Nakagawa T, Shimizu M, Shirakami Y, Tatebe H, Yasuda I, Tsurumi H, et al. Synergistic effects of acyclic retinoid and gemcitabine on growth inhibition in pancreatic cancer cells. Cancer Lett. 2009;273:250-6. 
66. Widschwendter M, Berger J, Daxenbichler G, Muller-Holzner E, Widschwendter A, Mayr A, et al. Loss of retinoic acid receptor beta expression in breast cancer and morphologically normal adjacent tissue but not in the normal breast tissue distant from the cancer. Cancer Res. 1997;57:4158-61.

67. Picard E, Seguin C, Monhoven N, Rochette-Egly C, Siat J, Borrelly J, et al. Expression of retinoid receptor genes and proteins in non-small-cell lung cancer. J Natl Cancer Inst. 1999;91:1059-66.

68. Liu ZM, Ding F, Guo MZ, Zhang LY, Wu M, Liu ZH. Downregulation of retinoic acid receptor- $\beta 2$ expression is linked to aberrant methylation in esophageal squamous cell carcinoma cell lines. World J Gastroenterol. 2004;10:771-5.

69. Leelawat K, Ohuchida K, Mizumoto K, Mahidol C, Tanaka M. All-trans retinoic acid inhibits the cell proliferation but enhances the cell invasion through upregulation of c-met in pancreatic cancer cells. Cancer Lett. 2005;224:303-10.

70. Schug TT, Berry DC, Toshkov IA, Cheng L, Nikitin AY, Noy N. Overcoming retinoic acid-resistance of mammary carcinomas by diverting retinoic acid from PPARbeta/delta to RAR. Proc Natl Acad Sci U S A. 2008;105:7546-51.

71. Gupta S, Pramanik D, Mukherjee R, Campbell NR, Elumalai S, de Wilde RF, et al. Molecular determinants of retinoic acid sensitivity in pancreatic cancer. Clin Cancer Res. 2012;18:280-9.

72. Perou CM, Sorlie T, Eisen MB, van de Rijn M, Jeffrey SS, Rees CA, et al. Molecular portraits of human breast tumours. Nature. 2000;406:747-52.

73. Sorlie T, Perou CM, Tibshirani R, Aas T, Geisler S, Johnsen H, et al. Gene expression patterns of breast carcinomas distinguish tumor subclasses with clinical implications. Proc Natl Acad Sci U S A. 2001;98:10869-74.

74. Riggs BL, Hartmann LC. Selective estrogen-receptor modulators mechanisms of action and application to clinical practice. New Engl J Med. 2003:348:618-29.

75. Fitzgerald $P$, Teng M, Chandraratna RA, Heyman RA, Allegretto EA. Retinoic acid receptor alpha expression correlates with retinoid-induced growth inhibition of human breast cancer cells regardless of estrogen receptor status. Cancer Res. 1997;57:2642-50.

76. Schneider SM, Offterdinger M, Huber $\mathrm{H}$, Grunt TW. Activation of retinoic acid receptor alpha is sufficient for full induction of retinoid responses in SK-BR-3 and T47D human breast cancer cells. Cancer Res. 2000;60:5479-87.

77. Centritto F, Paroni G, Bolis M, Garattini SK, Kurosaki M, Barzago MM, et al. Cellular and molecular determinants of all-trans retinoic acid sensitivity in breast cancer: luminal phenotype and RARa expression. EMBO Mol Med. 2015;7:950-72

78. Swift ME, Wallden B, Wayner EA, Swisshelm K. Truncated RAR beta isoform enhances proliferation and retinoid resistance. J Cell Physiol. 2006;209:718-25.

79. Tari AM, Lim SJ, Hung MC, Esteva FJ, Lopez-Berestein G. Her2/neu induces all-trans retinoic acid (ATRA) resistance in breast cancer cells. Oncogene. 2002:21:5224-32.

80. Liu RZ, Graham K, Glubrecht DD, Germain DR, Mackey JR, Godbout R. Association of FABP5 expression with poor survival in triple-negative breast cancer. Am J Pathol. 2011;178:997-1008.

81. Liu RZ, Garcia E, Glubrecht DD, Poon HY, Mackey JR, Godbout R. CRABP1 is associated with a poor prognosis in breast cancer: adding to the complexity of breast cancer cell response to retinoic acid. Mol Cancer. 2015;14:129.

82. Thulasiraman P, Garriga G, Danthuluri V, McAndrews DJ, Mohiuddin IQ. Activation of the CRABPII/RAR pathway by curcumin induces retinoic acid mediated apoptosis in retinoic acid resistant breast cancer cells. Oncol Rep. 2017;37:2007-15

83. Carrier M, Joint M, Lutzing R, Page A, Rochette-Egly C. Phosphoproteome and transcriptome of RA-responsive and RA-resistant breast Cancer cell lines. PLoS One. 2016;11:e0157290.

84. Masetti R, Biagi C, Zama D, Vendemini F, Martoni A, Morello W, et al. Retinoids in pediatric Onco-hematology: the model of acute promyelocytic leukemia and neuroblastoma. Adv Therapy. 2012;29:747-62

85. Peinemann F, van Dalen EC, Enk H, Berthold F. Retinoic acid postconsolidation therapy for high-risk neuroblastoma patients treated with autologous haematopoietic stem cell transplantation. Cochrane Database Syst Rev. 2017;8:CD010685.

86. Schnabel CA, Selleri L, Cleary ML. Pbx1 is essential for adrenal development and urogenital differentiation. Genesis. 2003;37:123-30.

87. Thiaville MM, Stoeck A, Chen L, Wu R-C, Magnani L, Oidtman J, et al Identification of PBX1 target genes in cancer cells by global mapping of PBX1 binding sites. PLoS One. 2012;7:e36054.

88. Shah N, Wang J, Selich-Anderson J, Graham G, Siddiqui H, Li X, et al. PBX1 is a favorable prognostic biomarker as it modulates 13-cis retinoic acid-mediated differentiation in neuroblastoma. Clin Cancer Res. 2014;20:4400-12.
89. Mao L, Ding J, Zha Y, Yang L, McCarthy BA, King W, et al. HOXC9 links cellcycle exit and neuronal differentiation and is a prognostic marker in neuroblastoma. Cancer Res. 2011;71:4314-24.

90. Tong J, Hannan F, Zhu Y, Bernards A, Zhong Y. Neurofibromin regulates G protein-stimulated adenylyl cyclase activity. Nat Neurosci. 2002;5:95-6.

91. Holzel M, Huang S, Koster J, Ora I, Lakeman A, Caron H, et al. NF1 is a tumor suppressor in neuroblastoma that determines retinoic acid response and disease outcome. Cell. 2010;142:218-29.

92. Eleveld TF, Oldridge DA, Bernard V, Koster J, Daage LC, Diskin SJ, et al. Relapsed neuroblastomas show frequent RAS-MAPK pathway mutations. Nat Genet. 2015;47:864-71.

93. Mosse YP, Maris JM. MEKing Retinoids Work Better. Cancer Cell. 2010;18:103-5.

94. Fischer-Huchzermeyer S, Dombrowski A, Wilke G, Stahn V, Streubel A, Mautner VF, et al. MEK inhibitors enhance therapeutic response towards ATRA in NF1 associated malignant peripheral nerve sheath tumors (MPNST) in-vitro. PLoS One. 2017;12:e0187700.

95. Tallini G, Dal Cin P. HMGI(Y) and HMGl-C dysregulation: a common occurrence in human tumors. Adv Anat Pathol. 1999;6:237-46.

96. Giannini G, Di Marcotullio L, Ristori E, Zani M, Crescenzi M, Scarpa S, et al. $\mathrm{HMGI}(Y)$ and $\mathrm{HMGl}-\mathrm{C}$ genes are expressed in neuroblastoma cell lines and tumors and affect retinoic acid responsiveness. Cancer Res. 1999:59:2484-92.

97. Cerignoli F, Ambrosi C, Mellone M, Assimi I, Di Marcotullio L, Gulino A, et al. HMGA Molecules in Neuroblastic Tumors. Ann N Y Acad Sci. 2004;1028:122-32.

98. Barral JM, Bauer CC, Ortiz I, Epstein HF. Unc-45 mutations in Caenorhabditis elegans implicate a CRO1/She4p-like domain in myosin assembly. J Cell Biol. 1998;143:1215-25.

99. Chadli A, Graham JD, Abel MG, Jackson TA, Gordon DF, Wood WM, et al. GCUNC-45 is a novel regulator for the progesterone receptor/hsp90 chaperoning pathway. Mol Cell Biol. 2006;26:1722-30.

100. Epping MT, Meijer LAT, Bos JL, Bernards R. UNC45A Confers Resistance to Histone Deacetylase Inhibitors and Retinoic Acid. Mol Cancer Res. 2009;7:1861-70.

101. Tassara M, Döhner K, Brossart P, Held G, Götze K, Horst H-A, et al. Valproic acid in combination with all-trans retinoic acid and intensive therapy for acute myeloid leukemia in older patients. Blood. 2014;123:4027-36.

102. Cowan AJ, Stevenson PA, Gooley TA, Frayo SL, Oliveira GR, Smith SD, et al. Results of a phase I-II study of fenretinide and rituximab for patients with indolent B-cell lymphoma and mantle cell lymphoma. Br J Haematol. 2017; 176:583-90.

103. Toma S, Raffo P, Nicolo G, Canavese G, Margallo E, Vecchio C, et al. Biological activity of all-trans-retinoic acid with and without tamoxifen and alpha-interferon 2a in breast cancer patients. Int J Oncol. 2000;17:991-1000.

104. Basu P, Jenson AB, Majhi T, Choudhury P, Mandal R, Banerjee D, et al. Phase 2 Randomized Controlled Trial of Radiation Therapy Plus Concurrent Interferon-Alpha and Retinoic Acid Versus Cisplatin for Stage III Cervical Carcinoma. Int J Radiat Oncol Biol Phys. 2016;94:102-10.

105. Duvic M, Hymes K, Heald P, Breneman D, Martin AG, Myskowski P, et al. Bexarotene is effective and safe for treatment of refractory advanced-stage cutaneous T-cell lymphoma: multinational phase II-III trial results. J Clin Oncol. 2001;19:2456-71.

106. Children's Oncology Group (CCG 09709), Villablanca JG, Krailo MD, Ames MM, Reid JM, Reaman GH, et al. Phase I trial of oral fenretinide in children with high-risk solid tumors: a report from the Children's Oncology Group (CCG 09709). J Clin Oncol. 2006;24:3423-30.

107. Zapletalova D, André N, Deak L, Kyr M, Bajciova V, Mudry P, et al. Metronomic chemotherapy with the COMBAT regimen in advanced pediatric malignancies: a multicenter experience. Oncology. 2012;82:249-60.

108. Penas-Prado M, Hess KR, Fisch MJ, Lagrone LW, Groves MD, Levin VA, et al. Randomized phase II adjuvant factorial study of dose-dense temozolomide alone and in combination with isotretinoin, celecoxib, and/or thalidomide for glioblastoma. Neuro-oncology. 2015;17:266-73.

109. High-Dose Chemotherapy Plus Autologous Stem Cell Transplantation Compared With Intermediate-Dose Chemotherapy Plus Autologous Stem Cell Transplantation With or Without Isotretinoin in Treating Young Patients With Recurrent High-Grade Gliomas - Full Text View - ClinicalTrials.gov. https://clinicaltrials.gov/ct2/show/NCT00078988.

110. Puduvalli VK, Yung WKA, Hess KR, Kuhn JG, Groves MD, Levin VA, et al. Phase II Study of Fenretinide (NSC 374551) in Adults With Recurrent Malignant Gliomas: A North American Brain Tumor Consortium Study. J Clin Oncol. 2004;22. https://doi.org/10.1200/JCO.2004.09.096.

111. Muto Y, Moriwaki H, Ninomiya M, Adachi S, Saito A, Takasaki KT, et al. Prevention of second primary tumors by an acyclic retinoid, polyprenoic 
acid, in patients with hepatocellular carcinoma. Hepatoma Prevention Study Group. N Engl J Med. 1996;334:1561-7.

112. Nijhof IS, Groen RWJ, Lokhorst HM, van Kessel B, Bloem AC, van Velzen J, et al. Upregulation of CD38 expression on multiple myeloma cells by all-trans retinoic acid improves the efficacy of daratumumab. Leukemia. 2015;29:2039-49.

113. Arrieta O, González-De la Rosa CH, Aréchaga-Ocampo E, VillanuevaRodríguez G, Cerón-Lizárraga TL, Martínez-Barrera L, et al. Randomized phase II trial of All-trans-retinoic acid with chemotherapy based on paclitaxel and cisplatin as first-line treatment in patients with advanced non-small-cell lung cancer. J Clin Oncol. 2010;28:3463-71.

114. Reynolds CP, Frgala T, Tsao-Wei DD, Groshen S, Morgan R, McNamara M, et al. High plasma levels of fenretinide (4-HPR) were associated with improved outcome in a phase II study of recurrent ovarian cancer: A study by the California Cancer Consortium. JCO. 2007;25(18_suppl):5555.

115. Stromal TARgeting for PAncreatic Cancer (STAR_PAC) - Full Text View ClinicalTrials.gov. https://clinicaltrials.gov/ct2/show/NCT03307148.

116. BRAF V600E and Redifferentiation Therapy in Radioiodine-refractory Papillary Thyroid Cancer - Full Text View - ClinicalTrials.gov. https://clinicaltrials.gov/ ct2/show/NCT03363347.

117. Moore MM, Stockler M, Lim R, Mok TSK, Millward M, Boyer MJ. A phase II study of fenretinide in patients with hormone refractory prostate cancer: a trial of the Cancer Therapeutics Research Group. Cancer Chemother Pharmacol. 2010;66:845-50

118. Vaishampayan U, Heilbrun LK, Parchment RE, Jain V, Zwiebel J, Boinpally RR, et al. Phase II trial of fenretinide in advanced renal carcinoma. Invest New Drugs. 2005;23:179-85.

119. Schneider BJ, Worden FP, Gadgeel SM, Parchment RE, Hodges CM, Zwiebel J, et al. Phase II trial of fenretinide (NSC 374551) in patients with recurrent small cell lung cancer. Invest New Drugs. 2009;27:571-8.

120. Lippman SM, Meyskens FL. Treatment of advanced squamous cell carcinoma of the skin with isotretinoin. Ann Intern Med. 1987;107:499-502.

121. Phase II Study Of Roferon and Accutane For Patients With T-Cell Malignancies - Full Text View - ClinicalTrials.gov. https://clinicaltrials.gov/ct2/ show/NCT00038376.

122. Hiller B, Bradtke J, Balz H, Rieder H. CyDAS Online Analysis Site. 2004. http://www.cydas.org/OnlineAnalysis/. Accessed 2 Feb 2018.

Ready to submit your research? Choose BMC and benefit from:

- fast, convenient online submission

- thorough peer review by experienced researchers in your field

- rapid publication on acceptance

- support for research data, including large and complex data types

- gold Open Access which fosters wider collaboration and increased citations

- maximum visibility for your research: over $100 \mathrm{M}$ website views per year

At $\mathrm{BMC}$, research is always in progress.

Learn more biomedcentral.com/submissions 